\title{
Single-pot synthesis of ordered mesoporous silica films with unique controllable morphology
}

\author{
Emma M. Björk, Fredrik Söderlind and Magnus Odén
}

\section{Linköping University Post Print}

\section{Tweet}

N.B.: When citing this work, cite the original article.

Original Publication:

Emma M. Björk, Fredrik Söderlind and Magnus Odén, Single-pot synthesis of ordered mesoporous silica films with unique controllable morphology, 2013, Journal of Colloid and Interface Science, (413), 1-7.

http://dx.doi.org/10.1016/j.jcis.2013.09.023

Copyright: Elsevier

http://www.elsevier.com/

Postprint available at: Linköping University Electronic Press

http://urn.kb.se/resolve?urn=urn:nbn:se:liu:diva-99856 


\title{
Single-pot synthesis of ordered mesoporous silica films with
}

\section{unique controllable morphology}

\author{
Emma M. Björk*, Fredrik Söderlind and Magnus Odén \\ Nanostructured Materials, Dept. of Physics, Chemistry and Biology, \\ Linköping University, SE-58183, Sweden
}

*Corresponding author:

E-mail: emmjo@ifm.liu.se; Phone: +46 (0)13 282543

E-mail addresses for other authors:

Fredrik Söderlind: freso@ifm.liu.se; Magnus Odén: magod@ifm.liu.se 


\section{Abstract}

2 Mesoporous silica films consisting of a monolayer of separated SBA-15 particles with

3 unusually wide and short pores grown on silicon wafers have been fabricated in a

4 simple single-pot-synthesis, and the formation of the films has been studied. A recipe

5 for synthesizing mesoporous silica rods with the addition of heptane and $\mathrm{NH}_{4} \mathrm{~F}$ at low

6 temperature was used and substrates were added to the synthesis solution during the

7 reaction. The films are $\sim 90 \mathrm{~nm}$ thick, have a pore size of $10.7-13.9 \mathrm{~nm}$ depending on the

8 hydrothermal treatment time and temperature, and a pore length of $200-400 \mathrm{~nm}$. All

9 pores are parallel to the substrate, open, and easy to access, making them suitable for

10 applications such as catalyst hosts and gas separation. The growth of the films is closely

11 correlated to the evolution of the mesoporous silica particles. Here, we have studied the

12 time for adding substrates to the synthesis solution, the evolution of the films with time

13 during formation, and the effect of hydrothermal treatment. It was found that the

14 substrates should be added within 30-60 s after turning off the stirring and the films are

15 formed within 10 min after addition to the synthesis solution. The study has yielded a

16 new route for synthesizing mesoporous silica films with a unique morphology.

\section{Key words:}

19 SBA-15, mesoporous silica, large pore, films, rods, film growth, particle formation 


\section{1. Introduction}

2 Mesoporous silica has gained much attention due to its wide range of possible

3 applications, such as catalysts, drug delivery systems, solar cells, and batteries. For

4 several applications, it is preferable to have the mesoporous material on a substrate as a

5 film, in comparison to a powder. Furthermore, the pore structure is crucial for various

6 applications [1-4], and it is desirable with pores accessible from the film surface [5].

7 This is easily obtained when the pores are non-cylindrical, but for several applications,

8 ordered, cylindrical pores are preferable over wormlike structures [6] or spherical pores

9 [7]. However, synthesis of mesoporous films with hexagonally ordered cylindrical pores

10 (SBA-15) [8,9] most often results in pores aligned parallel to the substrate surface[10],

11 which makes it difficult to access the large surface area of the material. Additionally,

12 the size of the pores in these films is not easily controlled, neither in width nor length.

13 In order to facilitate or increase the efficiency of mesoporous silica films in applications

14 such as catalysts, solar cells, and batteries, it is therefore of importance to control the

15 pore dimensions, and finally fabricate films with tuneable cylindrical pores that are easy

16 to access.

18 Mesoporous silica films are most often synthesized by spin- or dip coating techniques

19 using Evaporation-Induced Self-Assembly (EISA) [11-16]. When this method is used

20 for synthesizing SBA-15 films, the pores, which are oriented parallel to the substrate,

21 becomes long, often several microns in length, and therefore difficult to access, even

22 though the orientation of the pores can be tuned by the solution flow [17]. Furthermore,

23 pore sizes above $9 \mathrm{~nm}$ are very rare [11] and the structure often collapses in the

24 presence of water $[1,3,18]$. However, it is possible to synthesize SBA-15 films with 
1 pores perpendicular to the substrate by e.g. Electro-Assisted Self Assembly [19],

2 surface treatments with different block copolymers [20], or laser-induced patterning of

3 the substrate [21], but the majority of these methods are also based on EISA.

5 Mesoporous silica films can also be grown at interfaces, e.g. at the air-water interface

6 [22-24], or between bilayers [25]. However, the resulting pores are again most often

7 very long and parallel to the substrate, or freestanding and not attached to a substrate,

8 and hence they can be difficult to handle for various applications. Films can also be

9 synthesized by deposition of preformed nanoparticles in colloidal solutions [26], but in

10 this case it is the voids between particles that form the pores. Hence, the pore size and

11 structure is difficult to control, and cylindrical pores are not obtainable. On the other

12 hand, if the nanoparticles are mesoporous, with, e.g. cylindrical pores, a two step

13 process is required and the particles will be loosely attached on the surface. In order to

14 have a sustainable film with accessible, cylindrical pores, it would be preferable to

15 attach and grow separate particles with controllable length and pore size to substrates,

16 preferably with a simpel one-pot method in order to reduce the synthesis time.

18 Previously, we have shown that mesoporous silica with unusually wide and short pores

19 can be synthesized in various morphologies, where each morphology consists of

20 crystallites, free or in various constellations [27-29]. The separated particles have shown

21 excellent behaviour in applications such as immobilization of enzymes [30] and drug delivery [31], and the pore dimensions can easily be tuned by variations in the synthesis

23 conditions. In this work, we show that separate crystallites with a controllable pore size

24 of 10-14 nm can be grown on a substrate during the synthesis and we also report on the 
1 growth mechanisms of these films. This new method for synthesizing mesoporous films

2 offers pore dimensions that can easily be altered and pores that are easy to access (even

3 though the pores are parallel to the substrate) due to the substantial separation of the

4 particles.

5 


\section{2. Materials and methods}

2 2.1 Synthesis

3 Hydrochloric acid (purity $\geq 37 \%$, puriss. p.a., Fluka, ACS Reagent, fuming), triblock

4 copolymer $\mathrm{EO}_{20} \mathrm{PO}_{70} \mathrm{EO}_{20}(\mathrm{P} 123)$ (Aldrich), ammonium fluoride (purity $\geq 98.0 \%$,

5 puriss. p.a., ACS reagent, Fluka), tetraethyl orthosilicate (TEOS) (reagent grade, 98\%,

6 Aldrich), heptane (99\%, ReagentPlus ${ }^{\circledR}$, Sigma-Aldrich), hydrogen peroxide (purity

$730 \%$, Scharlau), ammonia (purity 25\%, Scharlau), and octadecyltrichlorosilane (OTS)

8 (purity $\geq 90 \%$, Aldrich) were used as received.

9

10 Preparation of substrates

11 4" Si-wafers were cut into $8 \times 8 \mathrm{~mm}^{2}$ pieces and used as substrates. The substrates were

12 first cleaned with standard Radio Corporation of America (RCA) cleaning (5 parts $\mathrm{H}_{2} \mathrm{O}$,

131 part $\mathrm{H}_{2} \mathrm{O}_{2}$ and 1 part $\mathrm{NH}_{3}$ at $85^{\circ} \mathrm{C}$ for $10 \mathrm{~min}$ ) followed by treatment in $\mathrm{HNO}_{3}$ in

14 ambient temperature for $5 \mathrm{~min}$ [32]. The wafers were then treated with OTS (1 mmol/l)

15 in a heptane solution for $10 \mathrm{~min}$. Prior to the use of the substrates they were dried in an

16 oven at $200^{\circ} \mathrm{C}$ for $2 \mathrm{~h}$.

17

$18 \quad$ Film synthesis

19 The synthesis of mesoporous silica was a variation of the protocol from Johansson et al.

20 [29]. In a typical synthesis $2.4 \mathrm{~g}$ of P123 and $0.028 \mathrm{~g}$ of $\mathrm{NH}_{4} \mathrm{~F}$ was dissolved in $80 \mathrm{ml}$

$21 \quad 1.83 \mathrm{M} \mathrm{HCl}$ solution in a $500 \mathrm{ml}$ round-bottomed flask. The mixture was stirred at 20

$22{ }^{\circ} \mathrm{C}$ until the polymer was dissolved. $1 \mathrm{ml}$ heptane was premixed with $5.5 \mathrm{ml}$ TEOS and

23 then added to the micellar solution. The synthesis was kept under vigorous stirring for 4 
$1 \mathrm{~min}$ and then under static conditions for $1 \mathrm{~h} .30 \mathrm{~s}$ into the static time the substrates were

2 immersed into the synthesis solution. The substrates were kept free in the solution and

3 were not attached in any specific position. After the reaction, the solution and substrates

4 were transferred to a PTFE flask for hydrothermal treatment at $100{ }^{\circ} \mathrm{C}$ for $24 \mathrm{~h}$. The

5 material not attached to the substrate was filtered and both this rest product and the

6 films were washed with distilled water. Finally, both the films and the rest products

7 were calcinated in air at $550{ }^{\circ} \mathrm{C}$ for $5 \mathrm{~h}$ with a ramp of $2{ }^{\circ} \mathrm{C} / \mathrm{min}$.

$9 \quad$ Variations in the synthesis conditions

10 In order to study the formation process of the films several different synthesis

11 experiments were performed. All substrates in each parameter study were immersed to

12 the same reaction solution to avoid artefacts from small compositional variations.

13 Following parameters were studied:

14 - the addition time, i.e. the time between turning off the stirring and the substrate

15 addition was varied between $0-180 \mathrm{~s}$. For each addition time, a small amount

16 of the synthesis solution was removed from the reaction flask and added to a

17 large amount of distilled water in order to quench the reaction in order to study

18 the correlation between the state of the reaction solution and the formation of the

19 films. This product was filtered and washed with distilled water at least three

20 times.

21 - the formation time, i.e. the time for which the substrates are in the solution

22 during the static time was varied between $5-180 \mathrm{~min}$.

23 - the hydrothermal treatment time was varied between $0-48 \mathrm{~h}$ and the

24 hydrothermal treatment temperature was varied between $80-130{ }^{\circ} \mathrm{C}$. 
2 An illustration of the choices made to produce what here is called the final film, i.e. the

3 optimum morphology, is seen in Figure 1. Each time parameter is varied separately

4 while the other are kept fixed at $30 \mathrm{~s}$ addition time, $1 \mathrm{~h}$ formation time and a

5 hydrothermal treatment of $100{ }^{\circ} \mathrm{C}$ for $24 \mathrm{~h}$. All synthesis parameters for each specific

6 sample are found in the supporting information, SI 1.

7

8

9 Figure 1. Illustration of the optimization route for the formation of mesoporous silica

10 films and the optimum synthesis parameters. The separately varied parameters are:

11 substrate addition time and particle evolution (row 1 and 2), formation time (row 3), and

12 hydrothermal treatment time (row 4). The optimized time for each parameter is marked

13 with a solid red line and the arrows illustrate that after the optimization, the time is reset to zero for the following parameter. 


\subsection{Characterization}

2 Scanning electron microscopy (SEM) was performed with a Leo 1550 Gemini Scanning

3 Electron Microscope operated at $3 \mathrm{kV}$ and a working distance of $3-5 \mathrm{~mm}$. Nitrogen

4 sorption isotherms for the rest products from the film synthesis were obtained with a

5 Micromeritics ASAP 2020 at $-196{ }^{\circ} \mathrm{C}$ with samples outgassed at $300{ }^{\circ} \mathrm{C}$ for $5 \mathrm{~h}$. Pore

6 size distribution was calculated from the adsorption isotherm using the KJS-

7 method[33] and the BET-surface area from a relative pressure of $0.08-0.20$. The total

8 pore volume was estimated at $\mathrm{P} / \mathrm{P}_{0}=0.975$.

9 Transmission electron microscopy (TEM) was performed with a FEI Tecnai G2 TF 20

10 UT microscope operated at $200 \mathrm{kV}$. TEM samples were prepared by dispersing the

11 product in acetone and depositing it on a carbon covered copper grid, except for the

12 cross section sample which was prepared by using Focused Ion Beam (FIB) technique

13 on a Carl Zeiss CrossBeam 1540 EsB system [34].

14 Small angle x-ray scattering was performed with a PANalytical Empyrean in

15 transmission mode, using $\mathrm{Cu} \mathrm{K} \alpha$ radiation.

16 The film adhesion was tested by ultrasonication of the films in water for $15 \mathrm{~min}$. The

17 substrates were dried and weighed before and after the sonication and the weights were

18 compared. A tape test was performed where ordinary scotch tape was attached to one

19 half of a film and then quickly pulled off. The tape was visually inspected, and the film

20 was analysed by SEM. 


\section{3. Results}

\section{2 \\ 3.1 Addition time and correlation to the synthesis solution}

3 Figure 2 shows the particle morphology and films with and without hydrothermal

4 treatment for samples. Each row shows samples at a specific addition time. In the first

5 column, samples from the synthesis solution removed at the addition time are shown;

6 the second column displays films formed on substrates with different addition time and

7 no hydrothermal treatment; and the third column shows hydrothermally treated films.

8 Looking at the material present in the synthesis solution (Figure 2, first column), it is

9 clear that for an addition time of $0 \mathrm{~s}$, there are only spherical particles (Figure 2 (a)), and

10 with increasing addition time the particles becomes elongated (Figure 2 (d)) and start to

11 aggregate (Figure $2(\mathrm{~g})$ ). At an addition time of $60 \mathrm{~s} \mathrm{(Figure} 2(\mathrm{j})$ ), 300-500 nm large

12 particles coexist with the non-aggregated, elongated particles, see Figure $2(\mathrm{~m})$ and $(\mathrm{p})$.

13 Finally, after $180 \mathrm{~s}$ there is a pure phase with ordered particles, see Figure 2 (s), these

14 particles are named the final rest product.

16 Simultaneously to the removal of parts of the synthesis solution, substrates were added.

17 Half of these substrates were calcinated without the hydrothermal treatment step, and

18 these are shown in the second column of Figure 2. On the substrate added first, there are

19 many elongated and ordered structures (Figure $2(\mathrm{~b})$ ), but these are smaller than the

20 particles in the final rest product. As the addition time is extended, ordered particles,

21 slightly narrower than the final rest product, attach to the substrate by a mesocellular

22 foam (MCF) [35], see (Figure $2(\mathrm{e}),(\mathrm{h}),(\mathrm{k}),(\mathrm{n})$ and (q)). The amount of MCF is

23 decreasing with increasing addition time and completely vanishes at an addition time of

$2490 \mathrm{~s}$ (Figure 2 (q)). For the film added when there are only final particles in the solution, 
1 there are no particles attached to the substrate, and only a foamy structure is observed,

2 see Figure $2(\mathrm{t})$. In the third column of Figure 2, substrates added at different additions

3 times followed by hydrothermal treatment prior to the calcination are shown. During the

4 hydrothermal treatment, it is obvious that more elongated particles attach to the films

5 (Figure 2 (c), (f), (i), (l) and (o)) and that the particles become wider. For the latest

6 addition time, $180 \mathrm{~s}$, there is only an unordered network of elongated pores on the

7 substrate. 

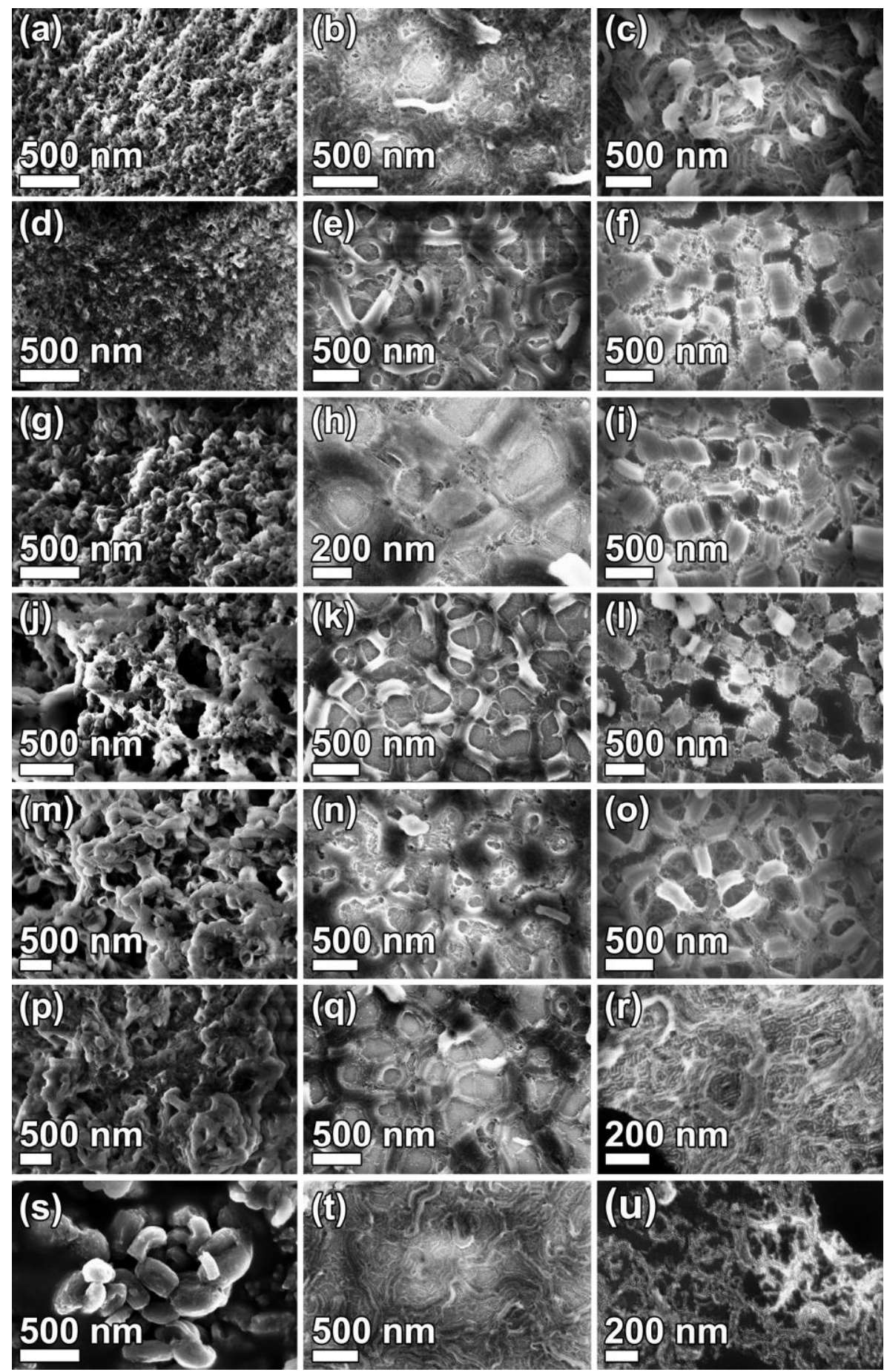

2 Figure 2. SEM micrographs of (column 1) particles withdrawn from the synthesis

3 solution at the time of substrate addition, (column 2) films without hydrothermal

4 treatment and (column 3) films with a hydrothermal treatment of $100{ }^{\circ} \mathrm{C}$ for $24 \mathrm{~h}$. The

5 addition times are (a)-(c) $0 \mathrm{~s}$, (d)-(f) $15 \mathrm{~s}$, (g)-(i) $30 \mathrm{~s}$, (j)-(l) $45 \mathrm{~s}$, (m)-(o) $60 \mathrm{~s}$, (p)-(r) 90

$\mathrm{s}$ and (s)-(u) $180 \mathrm{~s}$. 
1 The final film and the rest product have similar morphologies, i.e. separate particles that 2 are $300-400 \mathrm{~nm}$ long and $100-300 \mathrm{~nm}$ wide, with hexagonally ordered pores running 3 through the long axis of the particles, see Figure 3.

9 For the final film morphology, the foam only exists close to the mesoporous particles.

10 The substrate is visible between the particles and there is no particle overlap, indicating 11 a monolayer of particles, see Figure 4 (a). In Figure 4 (b) the foam and particles are

12 shown. It can be seen in this micrograph that the foam is porous (MCF) and does not

14 The cross section images, Figure 4 (c) show that the films are $~ 90$ nm thick; and Figure

154 (d) that the particles are grown at the substrate and not formed from free particles in 16 the reaction solution.

Figure 3. SEM and TEM micrographs of a film in (a) and (c) and the rest product from the film synthesis in (b) and (d). The inset in (c) shows the hexagonally ordered pore structure of the film. cover the mesoporous particles, or blocking their ends, but is attached to the substrate.
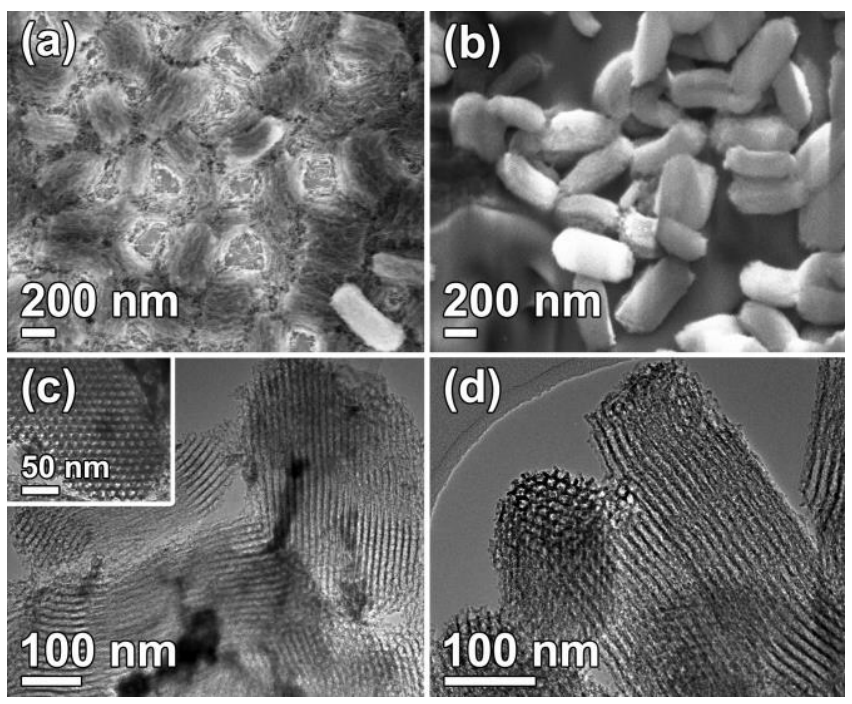

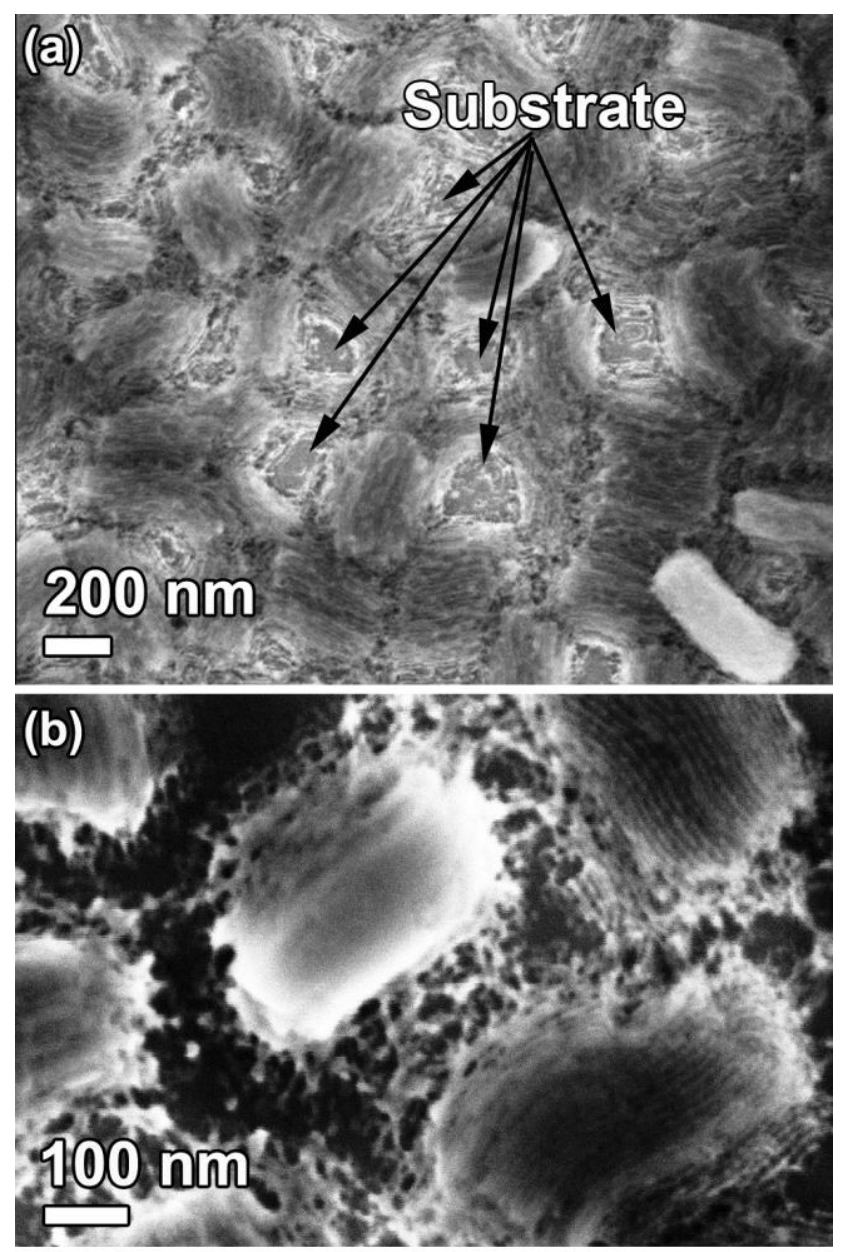

(c)

\section{0 ñm}

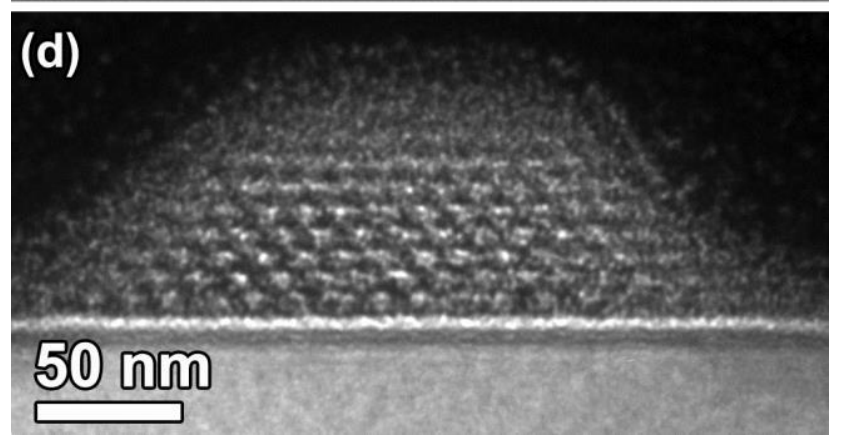

2 Figure 4. Close ups of the final film showing (a) the ordered particles with MCF close

3 to them and substrate in between, (b) that the particles are well separated and the pores

are open, (c) and (d) TEM micrographs of the film cross section. 
1 The films adhesion was tested by both ultrasonication for 15 minutes and tape testing.

2 Both methods show that the films adhere well to the substrate, and no film removal or

3 weight loss could be detected after the tests.

4

$5 \quad 3.2$ Formation time

6 After finding the optimum addition time at $30 \mathrm{~s}$, the time needed to form the films was

7 studied with SEM, illustrated in Figure 5. It is clear that the formation of particles on

8 the substrate is still ongoing $5 \mathrm{~min}$ after the substrate addition to the synthesis solution,

9 see Figure 5 (a). At this point, elongated particles have started to form, but they are

10 narrower compared to the final particles and are coated with the MCF. After $10 \mathrm{~min}$, the

11 film particles have reached the final shape and structure, which do not change for longer

12 synthesis times, see Figure $5(\mathrm{~b})-(\mathrm{d})$.

13
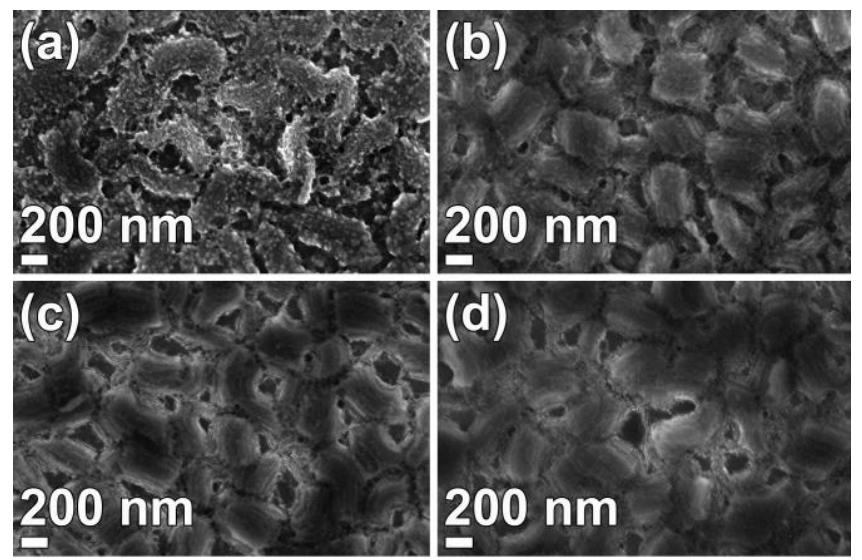

Figure 5. Samples synthesized with an addition time of $30 \mathrm{~s}$ and a formation time of (a) $5 \mathrm{~min}$, (b) $10 \mathrm{~min}$, (c) $20 \mathrm{~min}$ and (d) $180 \mathrm{~min}$.

\subsection{The morphological effects of hydrothermal treatment time}

Figure 6 shows SEM micrographs of films synthesized with $30 \mathrm{~s}$ addition time, $1 \mathrm{~h}$ formation time, and different hydrothermal treatment times. Without hydrothermal 
1 treatment only particles, with a very small amount of MCF, exist on the substrate

2 (Figure 6 (a)), and by extending the hydrothermal treatment time the amount of MCF

3 surrounding the particles is increased. After $12 \mathrm{~h}$ of hydrothermal treatment (Figure 6

4 (f)), there are no further changes in the film morphology.
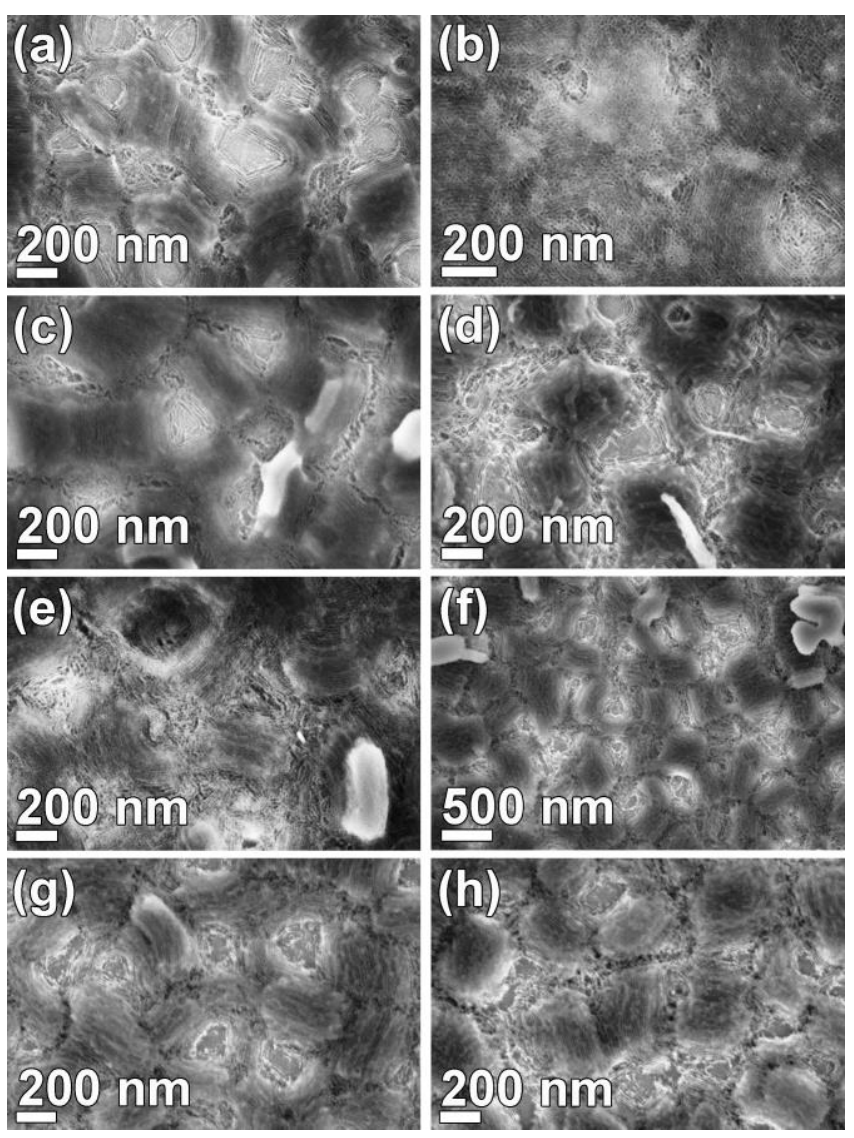

6 Figure 6. SEM micrographs of films synthesized with a hydrothermal treatment time of (a) $0 \mathrm{~h}$, (b) $0.5 \mathrm{~h}$, (c) $1 \mathrm{~h}$, (d) $2 \mathrm{~h}$, (e) $4 \mathrm{~h}$, (f) $12 \mathrm{~h}$, (g) $24 \mathrm{~h}$ and (h) $48 \mathrm{~h}$.

\subsection{Pore size control by hydrothermal treatment temperature}

10 The physiochemical properties of the material have been measured on the rest products

11 from the film syntheses, i.e. the rods. As shown in Figure 3, the size and shape of the

12 particles from the rest products are the same as for the particles forming the films. 
1 Hence, we see no reason not to assume identical pore sizes for the films as for the free 2 particles.
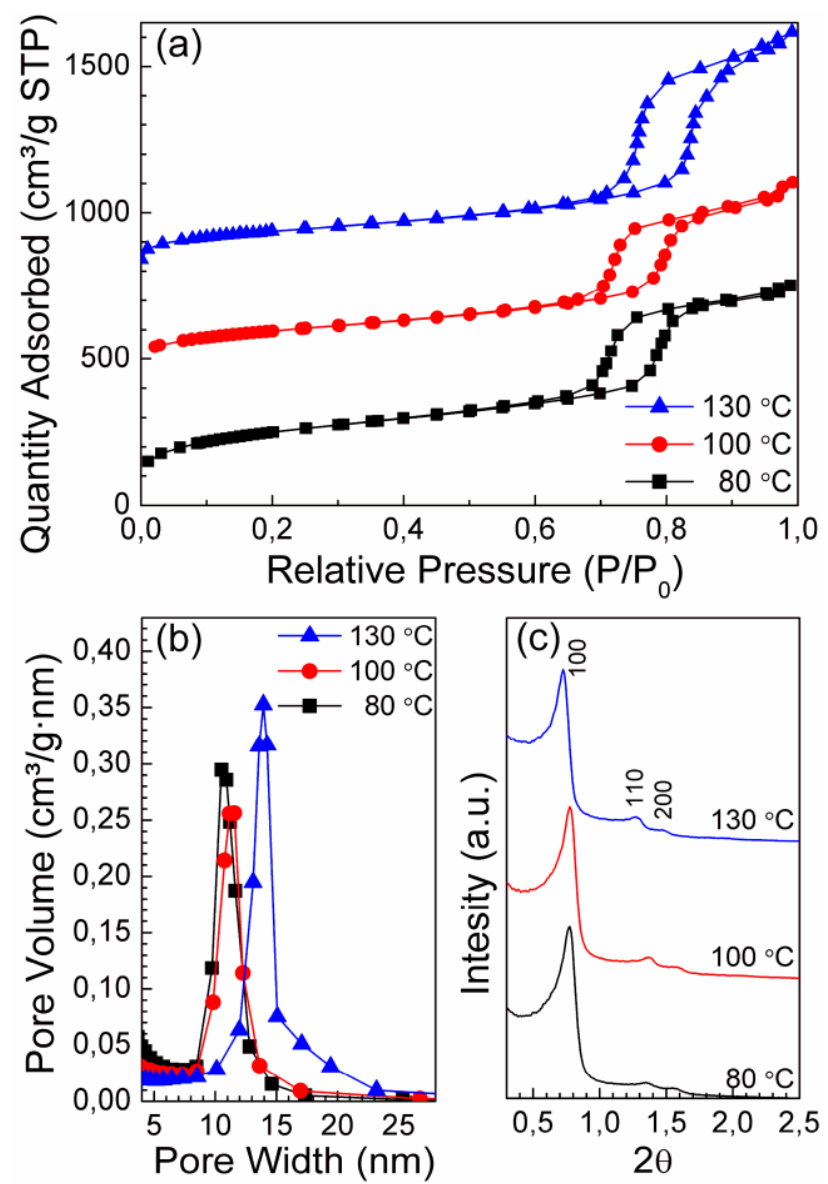

Figure 7. (a) Physisorption isotherms, (b) pore size distributions, and (c) X-ray diffractograms of samples synthesized with various hydrothermal treatment temperatures.

The effect of variations in the hydrothermal treatment temperature upon the pore size and unit cell parameter in the rest product is shown in Figure 7, and the data from the measurements are presented in Table I. The physisorption isotherms in Figure 7(a) show typical type IV isotherms with $\mathrm{H} 1$ hysteresis loops, characteristic for the cylindrical pores typical for SBA-15 type materials. The pore size distributions shown in Figure 7(b) are narrow, indicating a homogeneous mesopore size. The hexagonal pore order 
1 confirmed b x-ray diffractograms (Figure 7(c)) that show three well resolved peaks

2 corresponding to the hexagonal structure of SBA-15. The unit cell parameters presented

3 in Table I are the average of the calculated unit cells from the 100, 110, and 200

4 diffraction peaks. It is clear that a higher hydrothermal treatment temperature increases

5 both the pore size and unit cell parameter, and decreases the specific surface area of the

6 materials. Moreover, the hydrothermal treatment temperature does not affect shape or

7 amount of particles in the films, which is shown in Figure 8. However, the amount of

8 MCF is decreased with increasing temperature.

9
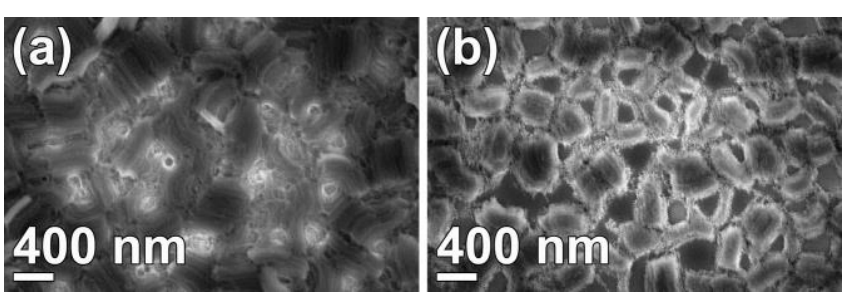

Figure 8. SEM micrographs of films synthesized with a hydrothermal treatment temperature of (a) $80{ }^{\circ} \mathrm{C}$ and (b) $130{ }^{\circ} \mathrm{C}$ for $24 \mathrm{~h}$. 


\section{4. Discussion}

\subsection{Formation}

3 The formation of the films can be correlated to the particle evolution in the synthesis

4 solution, and it is of importance to immerse the substrate into the synthesis solution at

5 the right time to gain the desired film morphology. It has previously been shown that

6 the particles in the SBA-15 synthesis are formed from spherical micelles that become

7 elongated upon the addition of the silica precursor. The elongated micelles aggregate,

8 resulting in the hexagonal structure of SBA-15. In an intermediate state, there is a

9 mixture of elongated, ordered micellar clusters and spherical micelles [36-38]. This

10 intermediate structure has also been observed in the system used here, at low

11 temperature with additions of heptane and $\mathrm{NH}_{4} \mathrm{~F}$ [29]. In that study, we showed that the

12 formation time of the rods is less than $5 \mathrm{~min}$, but it should be noted that even though the

13 particle morphology is completed within $5 \mathrm{~min}$, there is a continuous development of

14 the silica walls during the first hour.

16 From the results shown in Figure 2, it is clear that the formation steps of particles in the

17 synthesis solution are crucial for the formation of the films, and as shown in Figure 3,

18 the particles forming the films are identical in size and shape to the final rest product

19 (rods) formed in the solution. For the earliest addition times, the spherical micelles

20 attach to the substrate, forming the MCF. This structure is acting as glue between the

21 silicated micelles and the substrate, and its ability to bind larger structures is dependent

22 on the reactivity of the TEOS. The spherical micelles coexist with elongated micelles,

23 which can be seen in Figure 2(d), (g) and (k), for short addition times (15 - $45 \mathrm{~s})$, and

24 the elongated micelles will attach to the substrate and act as a nucleus for particle 
1 growth on the substrate. This is supported by the SEM micrographs in Figure 5. With a

2 formation time of $5 \mathrm{~min}$, narrow and elongated nuclei are attached to the substrate and

3 covered with foam. Silica coated micelles from the solution can attach to the elongated

4 nucleus, and the particles will form. After $10 \mathrm{~min}$, there is no more evolution of the film

5 morphology, see Figure 5 (b)-(d). It should be noted that a slightly shorter timescale

6 was shown for the rod morphology where the particle morphology was completed

7 within $5 \mathrm{~min}$, although the microstructure of the material was evolving for $60 \mathrm{~min}$ [29].

8 The formation is slower on the substrate, which probably is due to that the particle

9 growth is limited by the two dimensional environment imposed by the substrate. When

10 the larger aggregates are formed in the synthesis solution (addition times $60-90 \mathrm{~s}$ ), the

11 amount of spherical micelles is almost non-existent and the elongated particles are

12 formed on the substrate while foam is covering the substrate between the particles, see

13 Figure $2(\mathrm{~m})-(\mathrm{r})$. This is most probably a result from particles formed in the solution

14 before attaching to the nucleated particle on the substrate, which is less reactive due to a

15 more completed condensation of TEOS. A tentative illustration of the formation steps is

16 shown in Figure 1.

\subsection{The morphological effects of hydrothermal treatment time and temperature}

The effect of hydrothermal treatment is most often used to control the mesopore size

20 and microporosity of the material [29,39-41]. Increasing the hydrothermal treatment

21 time results in narrower physisorption hysteresis loops [40], and the effect of low

22 hydrothermal treatment temperatures/short times is similar to the effect of increasing the amount of TEOS in the synthesis solution, resulting in silica plugs in the pores $[42,43]$.

24 This was explained by Kruk et. al [40] as an effect of slow hydrolysis of TEOS in the 
1 PPO core of the micelles. When the hydrothermal treatment time was increased, the

2 slowly hydrolyzed TEOS can form constrictions inside the mesopores.

3 In our work, the excess TEOS is condensing onto the particles; hence the MCF becomes

4 more confined around the particles, and more particles from the synthesis solution is

5 attached in voids between those on the substrate, see Figure 6 . After $12 \mathrm{~h}$ of

6 hydrothermal treatment, there is not enough uncondensed TEOS in the solution to attach

7 more particles. Hence, there is no morphological change in the films when the

8 hydrothermal treatment time is increased further. The amount of foam decreases with

9 increased hydrothermal treatment temperature, shown in Figure 8. This behaviour is

10 assigned to a low hydrothermal stability of the foam.

\subsection{Pore size control by hydrothermal treatment temperature}

13 Variations in the hydrothermal treatment time and/or temperature are well known

14 methods to tune the pore size on the Ångström-level $[29,40,44]$. When increasing the

15 temperature, the hydrophilicity of the PEO chains is decreased. The chains then retract

16 from the silica network into the hydrophobic micellar core and expand it [44].

17 Furthermore, the increased hydrothermal treatment temperature decreases shrinkage of

18 the structure upon calcination, which also affects the pore size [40]. The results of

19 increasing the temperature are an increased pore size and decreased specific surface

20 area. The pore size for the films can be tuned between 10.7 and $13.9 \mathrm{~nm}$ by variations in

21 the hydrothermal treatment temperature. It should though be noted that the KJS-method

22 over estimates the pore size for pores larger than $12 \mathrm{~nm}$ [45], and the unit cell parameter

23 only varies between 13.1 and $14.0 \mathrm{~nm}$ when the hydrothermal treatment temperature is

24 increased. 


\section{5. Conclusions}

3 We have shown that mesoporous silica films consisting of a monolayer of short SBA-15

4 rods grown on OTS-treated silicon wafers can be realized in a single pot synthesis. The

5 films are attractive since the pores are easy to access, their thickness can be controlled

6 by the particle height, and the pore size tuned by the hydrothermal treatment. The

7 growth of the films is determined by the shape of silica-coated micelles formed in the

8 synthesis solution.

9 We also show that in order to achieve these films the different steps of the synthesis

10 must be optimized in terms of timing where both too short and too long times are

11 detrimental. The optimized synthesis has resulted in mesoporous SBA-15 films with

12 one of the largest reported pore size.

13 As a final remark, there are no silica waste products since the synthesis, apart from the

14 film formation, also yields free SBA-15 rods that are useful in various applications also

15 in its powder form.

17 6. Acknowledgement

18 The Swedish Research Council (VR), Linnaeus environment LiLi-NFM and Nanolith

19 Sverige $\mathrm{AB}$ are acknowledged for financial support. 
1 Reference List

2 [1] M. Etienne, A. Quach, D. Grosso, L. Nicole, C. Sanchez, A. Walcarius, Chem.

3 Mater. 19 (2007) 844-856.

4 [2] T. Wei, H.W. Hillhouse, Langmuir. 23 (2007) 5689-5699.

5 [3] C. Sanchez, C. Boissi Ã “re, D. Grosso, C. Laberty, L. Nicole, Chem. Mater. 20 (2008)

$6 \quad 682-737$.

7 [4] P. Innocenzi, L. Malfatti, G. Soler-Illia, Chem. Mater. 23 (2011) 2501-2509.

8 [5] K.C.-. - Wu, X. - Jiang, Y. - Yamauchi, - J. Mater. Chem. - 8934.

9 [6] S. Song, Y. Liang, Z. Li, Y. Wang, R. Fu, D. Wu, P. Tsiakaras, Applied Catalysis B:

10 Environmental. 98 (2010) 132-137.

11 [7] V. Cauda, L. Mühlstein, B. Onida, T. Bein, Microporous and Mesoporous Materials. $12118(2009)$ 435-442.

13 [8] D. Zhao, Q. Huo, J. Feng, B.F. Chmelka, G.D. Stucky, J. Am. Chem. Soc. 120 14 (1998) 6024-6036.

15 [9] D. Zhao, J. Feng, Q. Huo, N. Melosh, G.H. Fredrickson, B.F. Chmelka, G.D. Stucky, 16 Science. $279(1998) 548-552$.

17 [10] V.V. Guliants, M.A. Carreon, Y.S. Lin, Journal of Membrane Science. 235 (2004) $18 \quad 53-72$.

19 [11] D. Zhao, P. Yang, N. Melosh, J. Feng, B.F. Chmelka, G.D. Stucky, Adv Mater. 10 20 (1998) 1380-1385.

21 [12] D. Grosso, A.R. Balkenende, P.A. Albouy, A. Ayral, H. Amenitsch, F. Babonneau, 22 Chemistry of Materials. 13 (2001) 1848-1856.

23 [13] D. Grosso, F. Cagnol, G. . . Soler-Illia, E. . Crepaldi, H. Amenitsch, A. Brunet-

24 Bruneau, A. Bourgeois, C. Sanchez, Advanced Functional Materials. 14 (2004) 309-322.

25 [14] L.C. Huang, E.K. Richman, B.L. Kirsch, S.H. Tolbert, Microporous and

26 Mesoporous Materials. 96 (2006) 341-349.

27 [15] C. Liu, Y. Deng, J. Liu, H. Wu, D. Zhao, Microporous and Mesoporous Materials.

$28116(2008) 633-640$.

29 [16] P.C.A. Alberius, K.L. Frindell, R.C. Hayward, E.J. Kramer, G.D. Stucky, B.F.

30 Chmelka, Chem. Mater. 14 (2002) 3284-3294. 
1 [17] W. Cho, T. Kim, K. Char, C.L. Soles, Microporous and Mesoporous Materials. 131

2 (2010) 136-140.

3 [18] M. Yan, S. Dourdain, A. Gibaud, Thin Solid Films. 516 (2008) 7955-7961.

4 [19] A. Goux, M. Etienne, E. Aubert, C. Lecomte, J. Ghanbaja, A. Walcarius,

5 Chemistry of Materials. 21 (2009) 731-741.

6 [20] V.R. Koganti, S.E. Rankin, J Phys Chem B. 109 (2005) 3279-3283.

7 [21] B. Su, X. Lu, Q. Lu, Langmuir. 24 (2008) 9695-9699.

8 [22] R. Pitchumani, W. Li, M. Coppens, in: Abdelhamid Sayari and Mietek Jaroniec

9 (Ed.), Studies in Surface Science and Catalysis, Elsevier, 2005, pp. 83-88.

10 [23] R. Pitchumani, W. Li, M.-. Coppens, Catalysis Today. 105 (2005) 618-622.

11 [24] S.S. Park, C.-. Ha, Chemistry of Materials. 17 (2005) 3519-3523.

12 [25] B. Chen, H. Lin, M. Chao, C. Mou, C. Tang, Adv. Mater. 16 (2004) 1657-1661.

13 [26] T. Nypelö, M. Österberg, X. Zu, J. Laine, Colloids Surf. Physicochem. Eng.

14 Aspects. $392(2011) 313-321$.

15 [27] E.M. Johansson, J.M. Córdoba, M. Odén, Mater Lett. 63 (2009) 2129-2131.

16 [28] E.M. Johansson, J.M. Córdoba, M. Odén, Microporous and Mesoporous Materials.

$17133(2010) 66-74$.

18 [29] E.M. Johansson, M.A. Ballem, J.M. Córdoba, M. Odén, Langmuir. 27 (2011)

19 4994-4999.

[30] H. Gustafsson, E.M. Johansson, A. Barrabino, M. Odén, K. Holmberg, Colloids and Surfaces B: Biointerfaces. 100 (2012) 22-30.

[31] D. Sen Karaman, D. Desai, R. Senthilkumar, E. Johansson, N. Ratts, M. Oden, J. Eriksson, C. Sahlgren, D. Toivola, J. Rosenholm, Nanoscale Research Letters. 7 (2012) 358.

[32] W. Kern, D.A. Puotimen RCA Review. 31 (1970) 187-206.

[33] M. Kruk, M. Jaroniec, A. Sayari, Langmuir. 13 (1997) 6267-6273.

[34] R.M. Langford, A.K. Petford-Long, J. Vac. Sci. Technol. A. 19 (2001) 2186-2193.

28 [35] J.S. Lettow, Y.J. Han, P. Schmidt-Winkel, P. Yang, D. Zhao, G.D. Stucky, J.Y.

29 Ying, Langmuir. 16 (2000) 8291-8295. 
1 [36] S. Ruthstein, J. Schmidt, E. Kesselman, Y. Telmon, D. Goldfarb,

2 J. Am. Chem. Soc. 128 (2006) 3366-3374.

3 [37] V.L. Zholobenko, A.Y. Khodakov, M. Impéror-Clerc, D. Durand, I. Grillo, Adv.

4 Colloid Interface Sci. 142 (2008) 67-74.

5 [38] M. Imperor-Clerc, I. Grillo, A.Y. Khodakov, D. Durand, V.L. Zholobenko, Chem.

6 Commun. 0 (2007) 834-836.

7 [39] M. Impéror-Clerc, P. Davidson, A. Davidson, J. Am. Chem. Soc. 122 (2000)

$8 \quad 11925-11933$.

9 [40] M. Kruk, L. Cao, Langmuir. 23 (2007) 7247-7254.

10 [41] P.F. Fulvio, S. Pikus, M. Jaroniec, J. Mater. Chem. 15 (2005) 5049-5053.

11 [42] P. Van Der Voort, P.I. Ravikovitch, K.P. De Jong, M. Benjelloun, E. Van Bavel, 12 A.H. Janssen, A.V. Neimark, B.M. Weckhuysen, E.F. Vansant, J. Phys. Chem. B. 106 13 (2002) 5873-5877.

14 [43] E.B. Celer, M. Kruk, Y. Zuzek, M. Jaroniec, J. Mater. Chem. 16 (2006) 2824-2833.

15 [44] A. Galarneau, H. Cambon, F. Di Renzo, F. Fajula, Langmuir. 17 (2001) 8328-8335.

16 [45] M. Jaroniec, L.A. Solocyoc, Langmuir. 22 (2006) 6757-6760.

17 